\title{
Pengaruh Jenis Polimer Terhadap Reflection Loss Pada Polymer Matrix Composite (PMC) Barium Heksaferrit Sebagai Radar Absorbing Material (RAM)
}

\author{
Nabella Nurul Aini, Widyastuti, Rindang Fajarin \\ Jurusan Teknik Material dan Metalurgi, Fakultas Teknologi Industri, Institut Teknologi Sepuluh \\ Nopember (ITS) \\ Jl. Arief Rahman Hakim, Surabaya 60111 Indonesia \\ e-mail: wiwid@mat-eng.its.ac.id
}

\begin{abstract}
Abstrak - Komposit RAM pada umumnya tersusun dari material magnetik dan material dielektrik. Pada penelitian ini digunakan Barium Heksaferrit sebagai material magnetik dan polimer (PAni, PPy, dan PET) sebagai material dilelektik. Tujuan dari penelitian ini adalah untuk meningkatkan penyerapan gelombang elekromagnetik pada komposit RAM. Komposit RAM disintesis dengan metode polimerisasi oksidasi. Hasil komposit RAM dicampurkan pada cat epoxy dengan presentase $10 \%$ dari total massa, dan dilapiskan pada baja kapal grade A tipe AH 36 dengan variasi jenis polimer (PAni, PPy, dam PET) pada metode pelapisan Jaumann layer. Karakterisasi komposit RAM diuji dengan menggunakan pengujian FTIR, LCR-Meter, SEM dan VNA. Diperoleh penyerapan paling optimal pada komposit BaM/PAni-epoxy dengan metode Jaumann layer sebesar$17,403 \mathrm{~dB}$ pada frekuensi penyerapan $8,4 \mathrm{GHz}$.
\end{abstract}

Kata Kunci: Komposit RAM, Jenis polimer, Jaumann layer

\section{PENDAHULUAN}

$\mathrm{T}$ EKNOLOGI stealth merupakan perkembangan teknologi dibidang pertahanan yang bertujuan untuk meminimalisir respon dari gelombang elektromagnetik yang dipancarkan oleh radar, sehingga posisi atau letak suatu benda tidak terdeteksi. Kemampuan suatu bahan atau material untuk menyerap gelombang elektromagnetik dinamakan Radar Absorbing Material (RAM). Bahan utama pembuatan material RAM terdiri dari material magnetik dan material dielektrik. Material magnetik yang digunakan dalam penelitian ini adalah Barium Heksaferrit (BaM), sedangkan untuk material dielektrik menggunakan polimer konduktif.

Barium Heksaferrit atau sering disebut dengan $\mathrm{BaM}$ merupakan material magnetik yang memiliki struktur kristal heksagonal yang diaplikasikan untuk magnet permanen, perekam data dan penyerapan gelombang mikro. Barium Heksaferrit memiliki kelebihan antara lain magnetisasi relatif tinggi, kestabilan kimia yang baik, tahan korosi, serta memiliki sifat kemagnetan yang dapat diatur sesuai dengan aplikasi [1]. (BaM) dapat disintesis dengan menggunakan metode sol gel. Metode sol gel dipilih karena memiliki kelebihan yaitu memiliki tingkat homogenitas yang tinggi jika dibandingakan dengan metode yang lain seperti presipitasi hidrotermal, aerosol dan kristalisasi gas.

Polimer konduktif merupakan material yang mampu menghantarkan arus listrik. Sifat khusus yang dimiliki antara lain: mampu mengurangi refleksi dan penyerapan gelombang elektromagnetik jika dibandingkan dengan logam lainnya [2]. Diantara polimer-polimer konduktif, Poly(ethylene terephthalate (PET), Polipirol (PPy) dan Polianilin (PAni) adalah jenis polimer konduktif yang banyak digunakan dalam penelitian karena memiliki kelebihan mudah disintesis, kestabilan kimia di udara baik dan konduktivitas listrik yang tinggi [3]. Beberapa penelitian yang telah dilakukan oleh [4] mensintesis komposit RAM dengan menggunakan material $\mathrm{BaM} / \mathrm{PET}$ dengan metode Dallenbach layer pada ketebalan $6 \mathrm{~mm}$ di peroleh reflection loss sebesar $-13,507 \mathrm{~dB}$ dengan frekuensi 8,4 GHz. Kemudian penelitian yang dilakukan oleh [5] dengan mengunakan komposit BaM/PAni yang disintesis dengan menggunakan metode polimerisasi in-situ diperoleh reflection loss sebesar $-12,5 \mathrm{~dB}$ pada frekuensi 7,8 . Selanjutnya [6] juga meneliti tentang MnFe2O4/PPy dengan ketebalan 1.5 $\mathrm{mm}$ diperoleh reflection loss $-12 \mathrm{~dB}$ dengan frekuensi 11.3 GHz.

Untuk mendapatkan penyerapan yang optimum, berbagai penelitian telah dilakukan dalam rangka mengembangkan RAM salah satunya dengan memvariasikan jenis polimer, ketebalan dan metode pelapisan. Metode pelapisan merupakan salah satu metode yang dapat meningkatkan penyerapan gelombang elektromagnetik. Metode pelapisan ini terdiri dari Dallenbach layer, Salisbury screen, dan Jaumann layer. Penelitian [7] dengan menggunakan metode Dallenbach layer diperoleh nilai reflection loss $-12 \mathrm{~dB}$, sedangkan [8] dengan menggunakan metode Jaumann layer diperoleh reflection loss sebesar $-10 \mathrm{~dB}$. Oleh karena itu perlu adanya pengembangan lebih lanjut mengenai metode pelapisan. Pada penelitian ini, dilakukan sintesis komposit RAM dengan mencampurkan Barium Heksaferrit (BaM) dan polimer konduktif (PAni, PPy, dan PET) dengan menggunakan metode polimerisasi oksidasi. Metode ini dipilih karena hemat energi dan reagen yang 
dipakai mudah didapat. Penelitian ini difokuskan pada pengaruh jenis polimer pada metode pelapisan Jaumann layer terhadap reflection loss pada komposit RAM sebagai Radar Absorbing Material (RAM).

\section{METODOLOGI PENELITIAN}

\section{1) Material}

Material yang digunakan dalam sintesis komposit RAM (BaM/Pani, BaM/Ppy dan BaM/PET) antar lain: anilin $\left(\mathrm{C}_{6} \mathrm{H}_{5} \mathrm{NH}_{2}\right)$, poly(ethylene terephthalate) (PET), pyrrole $\left(\mathrm{C}_{4} \mathrm{H}_{4} \mathrm{NH}\right)$, Dodecyl Benzene Sulfonic Acid (DBSA), ammonium persulfate $\left(\left(\mathrm{NH}_{4}\right)_{2} \mathrm{~S}_{2} \mathrm{O}_{8}\right)$, dan aseton.Material tambahan yang digunakan adalah Barium Heksaferrit (BaFe12O19), polyol, isocyanate, dan cat epoxy.

\section{2) Sintesis komposit BaM/(PAni, PPy, PET)}

Komposit BaM/PAni dan BaM/Ppy disintesis dengan menggunakan metode polimerisasi dengan perbandingan Barium Heksaferrit dan monomer sebesar 30:70 Wt\%. Proses pembuatan diawali dengan mencampurkan monomer anilin atau pirol dengan larutan DBSA, selanjutnya kedua larutan diaduk dengan magnetic stirrer selama 15 menit sehingga larutan berubah warna menjadi keruh dan berbusa. Setelah larutan tercampur kemudian ditambahkan dengan serbuk Barium Heksaferrit (BaM) sehingga larutan akan berubah warna menjadi hitam kemudian diaduk selama 15 menit. Larutan yang telah diaduk tersebut kemudian ditambahkan dengan ammonium persulfate (APS) yang berperan sebagai oksidator atau inisiator, penambahan APS bertujuan agar larutan tersebut membentuk endapan hijau untuk BaM/PAni dan endapan hitam untuk BaM/PET. Hasil endapan tersebut disaring dan dicuci dengan aseton dan aquades serta dikeringkan kurang lebih selama 24 jam.

Selanjutnya sintesis komposit BaM/PET disintesis dengan mencampurkan serbuk BaM dan PET dalam bentuk pallet dengan perbandingan 30:70Wt\% kemudian dilelehkan pada temperatur $260^{\circ} \mathrm{C}$ hingga membentuk gumpalan komposit $\mathrm{BaM} / \mathrm{PET}$ yang homogen. Hasil gumpalan tersebut kemudian dihaluskan agar membentuk serbuk komposit BaM/PET.

\section{3) Proses Pelapisan}

Setelah semua komposit BaM/(PAni, PPy, dan PET) terbentuk, kemudian dicampurkan dengan cat epoxy dengan perbandingan 10:90\%Wt. Selanjutnya melakukan preparasi baja kapal grade A tipe AH36 agar sesuai dengan standart pengujian. Setelah selesai preparasi, campuran cat dan komposit dilapiskan pada baja kapal pada ketebalan $2 \mathrm{~mm}$ dengan metode pelapisan Jaumann layer dan dikeringkan selama 3 hari.

\section{4) Karakterisasi}

Setelah proses pelapisan selesai, akan dilakukan beberapa pengujian untuk mengetahui karakterisasi dari serbuk komposit RAM dan pelapisan komposit RAM. Beberapa pengujian yang dilakukan anatar lain : pengujian SEM-EDX
FEI 850 dilakukan dengan tujuan untuk mengetahui struktur mikro dan morfologi pada permukan sampel. Kemudian pengujian FTIR dilakukan untuk mengetahui ikatan dan gugus fungsi yang terbentuk pada sampel. Pengujian konduktivitas listrik (LCR-Meter) dengan merek HIOKI bertujuan untuk mengetahui konduktivitas listrik sampel, dan terakhir pengujian VNA digunakan untuk mengetahui nilai reflection loss pada sampel yang terbentuk.

\section{ANALISA DATA DAN PEMBAHASAN}

\section{1) Hasil uji SEM-EDX}

Pada pengujian SEM-EDX ini digunakan untuk mengetahui struktur mikro dan bentuk morfologi dari material Barium Heksaferrit, jenis polimer (PAni, PPy, PET), komposit RAM dan lapisan coating pada komposit RAM. Hasil pengujian SEM ditunjukkan pada Gambar 1a menunjukkan bahwa partikel Barium Heksaferrit memiliki bentuk polygonal serta terdapat pori-pori pada permukaannya, sedangkan hasil pengujian SEM pada polimer PAni dan PPy (Gambar 1b,c) memiliki bentuk morfologi yang sama yaitu berbentuk globular dan ditemukan adanya agglomerasi akibat dari sisa pelarut. Selanjutnya Gambar 1d memperlihatkan bentuk morfologi dari PET yang terlihat berserat dan homogen.

Setelah material Barium Heksaferrit dan polimer (PAni, PPy, PET) terbentuk, kemudian dikompositkan menjadi komposit BaM/PAni, BaM/PPy, dan BaM/PET (Gambar 1eg) yang memiliki bentuk morfologi yang serupa yaitu berbentuk globular, dimana pada komposit BaM/Pani dan $\mathrm{BaM} / \mathrm{PPy}$ partikel BaM memiliki bentuk morfologi heksagonal dan poligonal. Sementara itu pada komposit BaM/Pani terjadi agglomerasi atau penggumpalan yang disebabkan oleh adanya sisa pelarut dari proses polimerisasi [9].
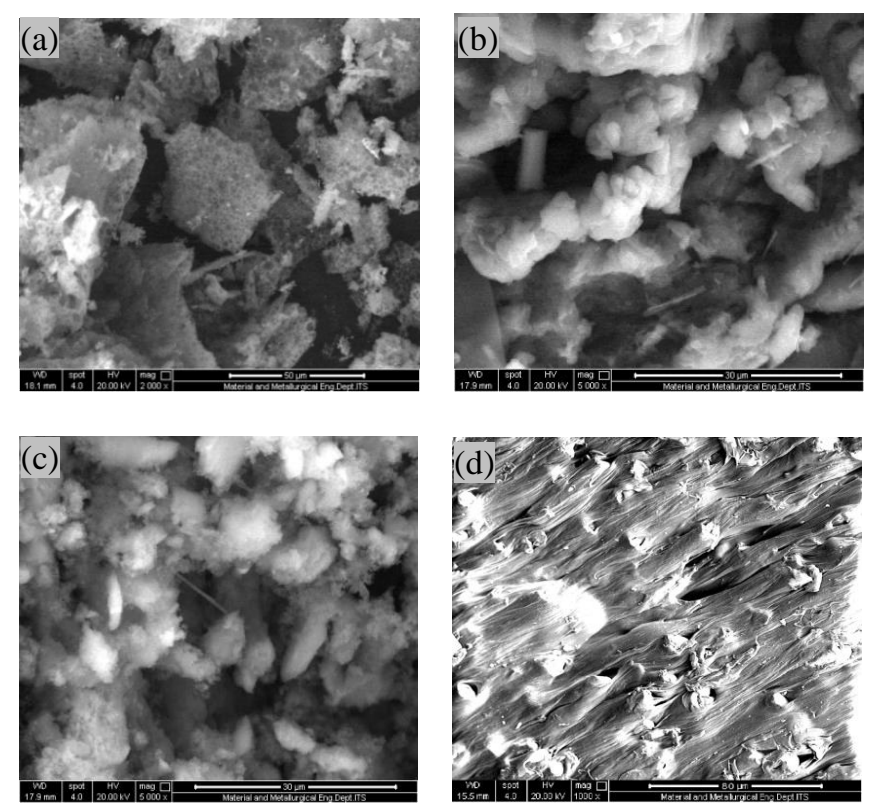

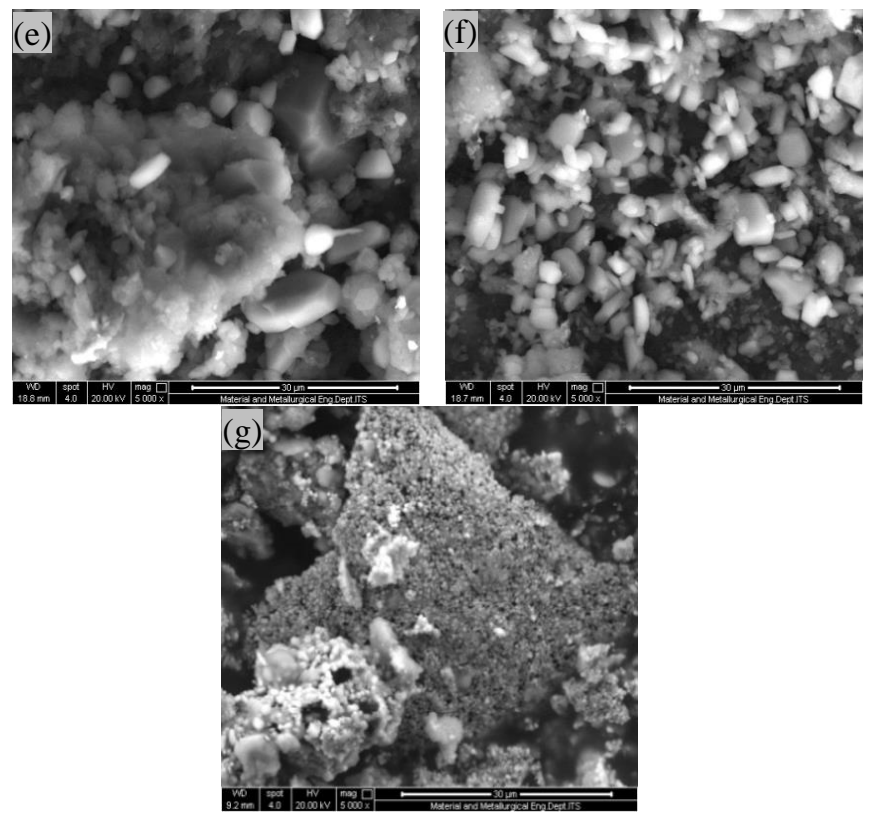

Gambar 1. Hasil SEM(a) BaM 2000x (b) PAni 5000x (c) PPy 5000x (d) PET 1000x (e) komposit BaM/Pani 5000x (f) BaM/PPy 5000x (g) BaM/PET $5000 x$

Untuk mengetahui distribusi komposisi yang terjadi pada partikel dan menyakinkan bahwa penambahan Barium Heksaferrit dan polimer (Pani, PPy, dan PET) ke dalam komposit $\mathrm{BaM} /($ Pani, Ppy, PET) yang telah terbentuk, maka dilakukan pengujian EDX pada area tertentu sehingga didapatkan komposisi secara umum.

Berdasarkan hasil pengujian EDX menunjukkan bahwa komposit $\mathrm{BaM} /($ PAni, PPy dan PET) pada (Gambar 2 e-g) memunculkan unsur $\mathrm{Ba}, \mathrm{Fe}, \mathrm{Zn}, \mathrm{O}, \mathrm{C}, \mathrm{S}, \mathrm{N}$ dan $\mathrm{Ni}$, dimana unsur $\mathrm{Ba}, \mathrm{Fe}, \mathrm{Zn}$, dan $\mathrm{O}$ adalah unsur yang dimiliki oleh Barium Heksaferrit (BaM), hal tersebut dibuktikan dengan hasil EDX dari Barium Heksaferrit (Gambar 2a) sedangkan pada unsur $\mathrm{C}, \mathrm{S}, \mathrm{N}$, dan $\mathrm{O}$ adalah unsur yang dimiliki oleh polimer (PAni, PPy dan PET), sehingga dapat disimpulkan bahwa komposit BaM/PAni, BaM/PPy, dan BaM/PET telah terbentuk.
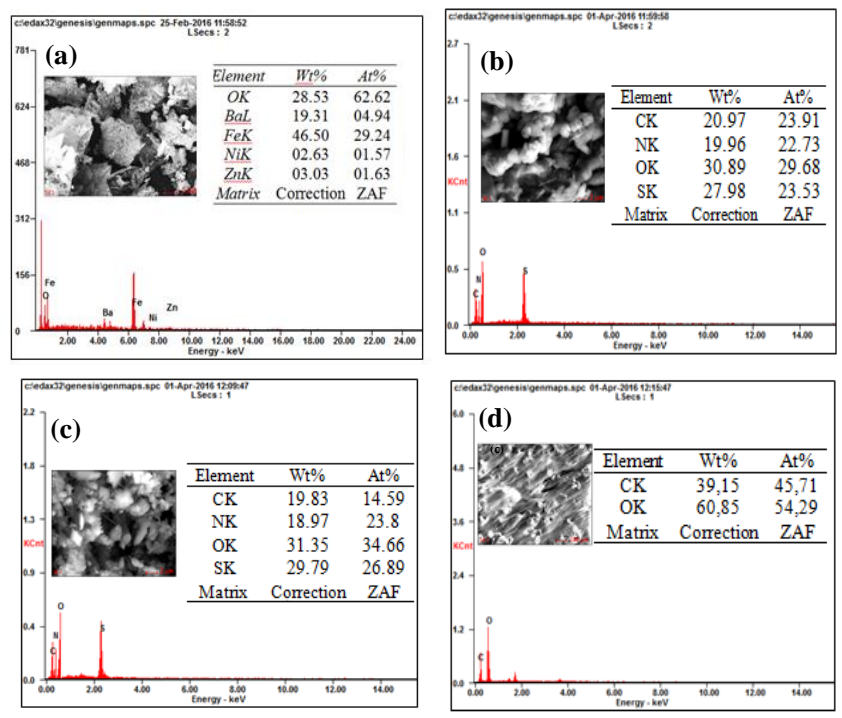
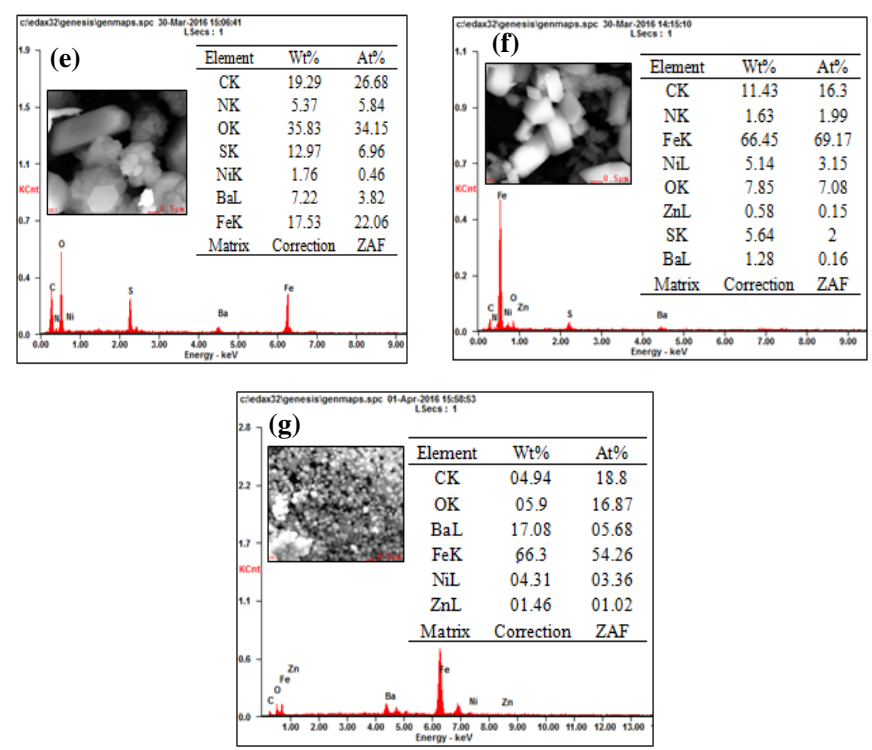

Gambar 2. Hasil sampel EDX pada komposit (a) BaM (b) PAni (c) PPy (d) PET (e) BaM/PAni (f) BaM/PPy (g) BaM/PET

Selanjutnya hasil uji SEM pada Gambar 3 menunjukkan morfologi permukaan melintang dari lapisan komposit $\mathrm{BaM} /($ Pani, Ppy, PET) dengan metode Jaumann layer yang memiliki bentuk morfologi hampir sama yang ditandai dengan adanya partikel $\mathrm{BaM}$ yang unmelted [10]. Serta terdapat $\mathrm{Pu}$ foam yang berperan sebagai bandgap, dimana morfologi pada PU foam terlihat jelas pada Gambar 3d.
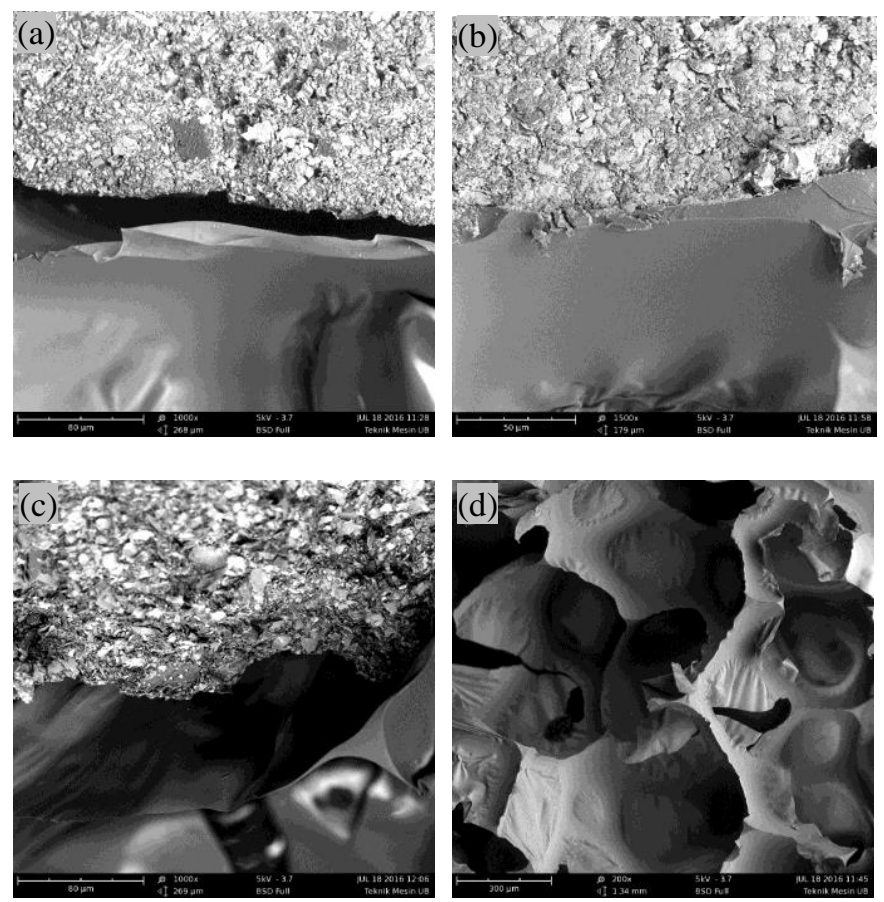

Gambar 3. SEM coating pemukaan melintang a) BaM/PAni Jaumann layer 1000x (b) BaM/PPy Jaumann layer 1500x (c) BaM/PET Jaumann layer 1000x (d) Pu foam 


\section{2) Hasil pengujian FTIR}

Pengujian FTIR dilakukan dengan tujuan untuk mengetahui gugus fungsi dan ikatan yang terbentuk pada sampel. Gambar 4 menunjukkan hasil pengujian FTIR.
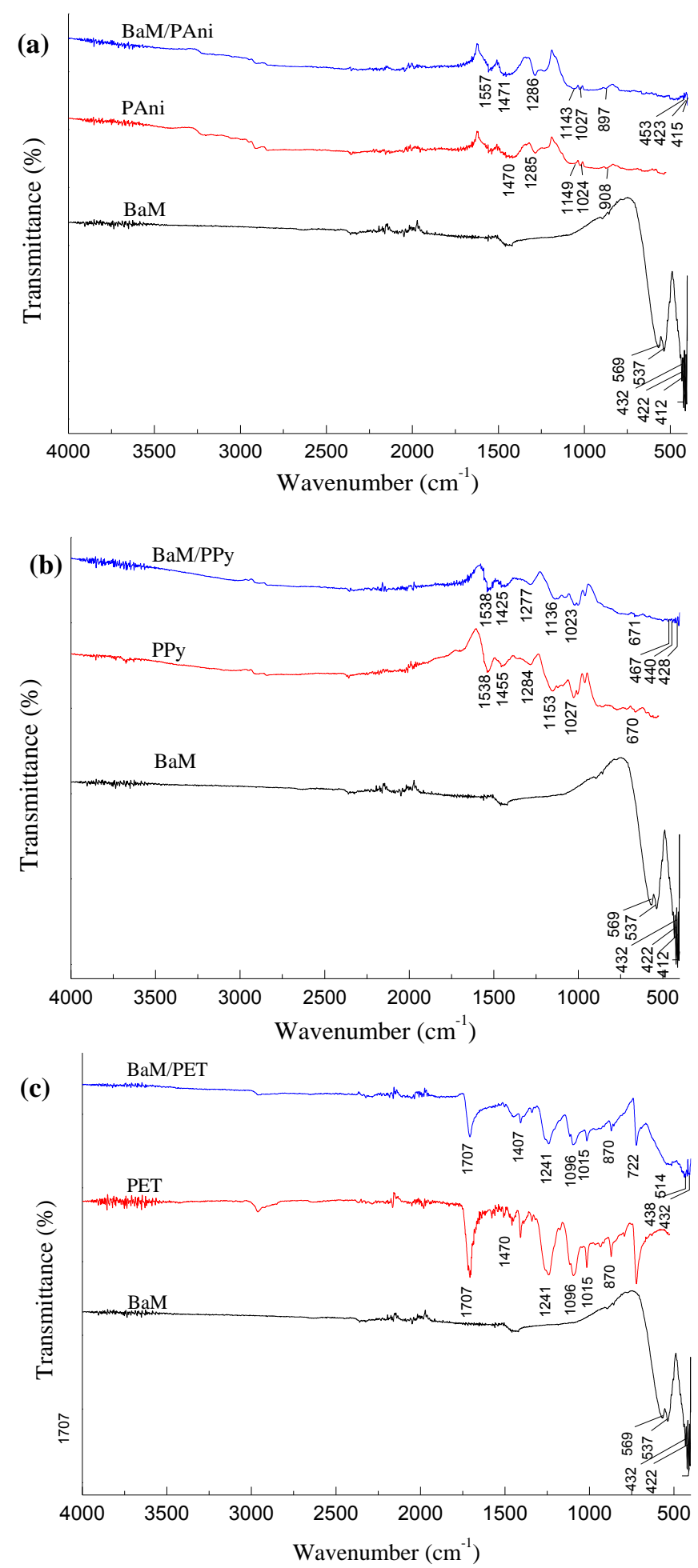

Gambar 4. Hasil FTIR (a) BaM, PAni, komposit BaM/PAni (b) BaM, PPy, komposit BaM/PPy (c) BaM, PET, komposit BaM/PET.

Berdasarkan grafik hasil pengujian FTIR menunjukkan terdapat beberapa lembah yang terbentuk yang dapat dianalisa untuk mengetahui gugus ikatan yang terdapat pada sampel.
Berdasarkan grafik hasil uji FTIR menunjukkan bahwa gugus fungsi dan ikatan pada komposit RAM (BaM/PAni, BaM/PPy, $\mathrm{BaM} / \mathrm{PET}$ ) tidak jauh berbeda dengan gugus ikatan yang dimiliki oleh polimernya. Sementara peak yang berada pada wave number 1149 dan $1143 \mathrm{~cm}^{-1}$ ditemukan regangan $\mathrm{S}=\mathrm{O}$ yang menunjukkan adanya dopan DBSA pada PAni, seperti yang dilaporkan [1], sedangkan pada wave number 1027 dan $1023 \mathrm{~cm}^{-1}$ menunjukkan adanya regangan $\mathrm{S}=\mathrm{O}$ dari dopan DBSA pada polimer PPy. Peak yang berada pada range 400500 dan 500-600 $\mathrm{cm}^{-1}$ pada komposit BaM/(PAni, PPy, dan PET ) menunjukkan adanya ikatan regangan $\mathrm{M}-\mathrm{O}$ yaitu metal oxide yang merupakan karakteristik dari terbentuknya BaM, hal tersebut juga dibuktikan pada hasil pengujian FTIR pada sampel Barium Heksaferrit $(\mathrm{BaM})$ yang memiliki wave number 569, 537, 432, 422, dan $412 \mathrm{~cm}^{-1}$ yang merupakan karakteristik absorbsi ikatan regangan M-O. Sehingga dapat disimpulkan bahwa tidak adanya ikatan baru yang menunjukkan bahwa material komposit RAM BaM/(PAni, PPy, PET) telah berhasil terbentuk.

\section{3) Hasil uji Konduktivitas Listrik}

Pengujian konduktivitas listrik diukur dengan menggunakan peralatan LCR-Meter merek HIOKI. Tujuan dilakukan pengujian ini adalah untuk mengetahui nilai konduktivitas listrik dari sampel. Berikut hasil pengujian konduktivitas listrik untuk polimer (Pani, PPy, PET) dan komposit BaM/(PAni, Ppy, PET):

Tabel 1

Nilai konduktivitas listrik

\begin{tabular}{cc}
\hline \hline Jenis Material & Nilai Konduktivitas Listrik $(\mathrm{S} / \mathrm{cm})$ \\
\hline PAni & $8.79809 \times 10^{-8}$ \\
BaM/PAni & $1.77744 \times 10^{-5}$ \\
PPy & $1.5007 \times 10^{-7}$ \\
BaM/PPy & $8.68413 \times 10^{-6}$ \\
PET & $1.47397 \times 10^{-9}$ \\
BaM/PET & $1.0354 \times 10^{-5}$ \\
\hline \hline
\end{tabular}

Berdasarkan hasil pengujian konduktivitas listrik pada Tabel 1 menunjukkan bahwa nilai konduktivitas tertinggi dimiliki oleh material komposit BaM/Pani sebesar $1.77744 \mathrm{x}$ $10^{-5} \mathrm{~S} / \mathrm{cm}$. Sedangkan untuk komposit BaM/PPy dan $\mathrm{BaM} / \mathrm{PET}$ memiliki nilai konduktivitas listrik yang lebih rendah, hal tersebut menunjukkan bahwa peningkatan nilai konduktivitas listrik dipengaruhi oleh konsentrasi dopan dan proses sintesis [7]. Dimana semakin konduktif suatu polimer maka semakin efektif untuk menyerap medan listrik dari gelombang elektromagnetik.

\section{4) Hasil Uji VNA}

Pengujian Vector Networ Analyzer (VNA) dengan tipe Advantest R3770 networ analyzer $300 \mathrm{KHz}-20 \mathrm{GHz}$ digunakan untuk mengukur nilai reflection loss pada lapisan komposit RAM (BaM/PAni, BaM/PPy, BaM/PET) dengan metode Juamann layer pada ketebalan $2 \mathrm{~mm}$. Daerah penyerapan yang 
digunakan pada daerah X-band dengan frekuensi $8-12 \mathrm{GHz}$. Berikut Gambar 5 dan Tabel 2 hasil pengujian VNA.

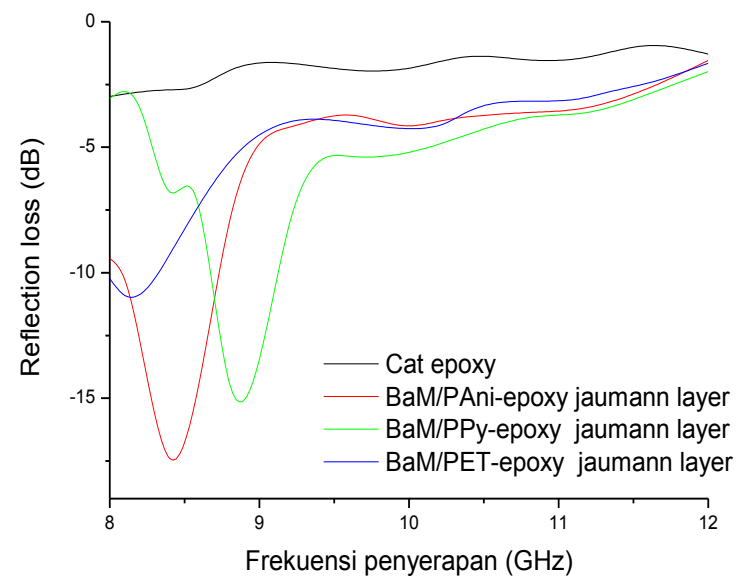

Gambar 5. Hasil pengujian VNA Cat epoxy, BaM/PAni Jaumann layer, $\mathrm{BaM} / \mathrm{PPy}$ Jaumann layer, dan BaM/PET Jaumann layer.

Tabel 2

Nilai reflection loss pada campuran cat epoxy dan material komposit RAM.

\begin{tabular}{ccc}
\hline Material & $\begin{array}{c}\text { Reflection loss } \\
(\mathrm{dB})\end{array}$ & $\begin{array}{c}\text { Frekuensi } \\
\text { penyerapan } \\
(\mathrm{GHz})\end{array}$ \\
\hline Cat epoxy & -2.977 & 8 \\
BaM/PAni-epoxy & -17.403 & 8.4 \\
BaM/PPy-epoxy & -14.424 & 8.8 \\
BaM/PET-epoxy & -10.232 & 8 \\
\hline \hline
\end{tabular}

Berdasarkan hasil pengujian VNA diperoleh nilai reflection loss tertinggi dimiliki oleh metode pelapisan Jaumann layer pada komposit BaM/PAni-epoxy dengan nilai reflection loss sebesar -17.403 dB pada freskuensi $8.4 \mathrm{GHz}$, kemudian komposit BaM/PPy-epoxy dengan nilai reflection loss sebesar $-14.424 \mathrm{~dB}$ pada frekuensi $8.8 \mathrm{GHz}$ dan terakhir pada komposit BaM/PET-epoxy dengan nilai reflection loss sebesar $10.232 \mathrm{~dB}$ pada frekuensi $8 \mathrm{GHz}$. Berdasarkan hasil tersebut dapat diketahui bahwa komposit BaM/PAni-epoxy memiliki nilai reflection loss terbesar dibandingkan dengan komposit $\mathrm{BaM} / \mathrm{PPy}$ dan komposit BaM/PET. Dimana semakin negatif atau besar nilai reflection loss maka semakin besar pula daya serap material terhadap gelombang mikro [11].

\section{KESIMPULAN}

Berdasarkan penelitian yang telah dilakukan dapat disimpulkan bahwa dengan adanya variasi jenis polimer (PAni, PPy, PET) yang telah disintesis menjadi komposit RAM, dapat diketahui bahwa penyerapan paling optimum dimiliki oleh lapisan Jaumann layer pada material komposit BaM/PAniepoxy dengan nilai reflection loss sebesar $-17.403 \mathrm{~dB}$ pada frekuensi penyerapan $8.4 \mathrm{GHz}$. Hal tersebut disebabkan adanya pengaruh konduktivitas listrik. Semakin konduktif semakin effektif menyerap medan listrik dari gelombang elektromagnetik

\section{DAFTAR PUSTAKA}

[1] Paul, K. B. M. 2007. Physica B, 388.

[2] Feng.Y.B., Qui T., Shen C.Y. 2007. "Absorbing properties and Struktural design of Microwave Absorber based on Carbonil Iron and Barium Ferrite". Jurnal of Magnetism and Magnetic Material, vol. 318, pp. 8-13.

[3] Buchari.,Noviandri,Indra.,Gandasasmita,Suryo., 2004."Study Of Electropolimerization Processes Of Pyrrole By Cyclic Voltametric Technique". Chemistry Department Faculty of Mathematics and Natural Sciences.Gadjah Mada University.Yogyakarta

[4] Rinata,Adelia,.2011."Pengaruh Presentasi Berat Barium Heksaferit $\left(\mathrm{BaFe}_{12} \mathrm{O}_{19}\right)$ dan Ketebalan Lapisan Terhadap Reflection Loss Pada Komposit Radar Absorbent Material (RAM)" Teknik Material dan Metalurgi.FTI,ITS. Surabaya.

[5] Yang, C.C., Gung, Y.J., Shih, C.C., Hung, W.C., Wu, K.H., 2009. "Synthesis, infrared and microwave absorbing properties of $\mathrm{BaTiO}_{3} /$ Polyanilin and $\mathrm{BaFe}_{12} \mathrm{O}_{19}$ /polyaniline and composite". Chemical Systems Research Division.Chung Shan Institute of Science and Technology.Taiwan

[6] Hossein, Seyed and Ahmad Asadnia.2012. "Synthesis, Characterization and Microwave-Absorbing Properties of Polypyrolle/ $\mathrm{MnFe}_{2} \mathrm{O}_{4}$ Nanocomposite". Departement of chemistry Faculty of science Islamic Azad University.

[7] Amalia, Lita.2014. "Pelapisan Multilayer dengan Metode Dallenbach Layer Menggunakan Polianilin dan Barium M-Heksaferrite sebagai Radar Absorbing Material (RAM)," Laporan Tesis Jurusan Fisika.Institut Teknologi Sepuluh Nopember Surabaya.

[8] Park, Ki-Yeon,.Sang-Eui Lee.,Chun-Gon Kim.,Jae-Hung Han.2006. "Fabrication and Electromagnetik Characteristics of Electromagnetic Wave Absorbing Sandwich Struktures". Departement Aerospace Engineering, Korea Advance of Science and Technology. Republic of Korea.

[9] Jiang J., L-Hong Ai., Da-Bin Qin., Hui Liu., Liang-Chao Li. 2009. "Preparation and Characterization of Electromagnetic Functionalized Polyaniline/ $\mathrm{BaFe}_{12} \mathrm{O}_{19}$ Composite," Laboratory of Applied Chemistry and Pollution Control Technology. China.

[10] Lisjak D., Lintunen P., Hujanen A., Varis T., Bolelli G., Lusvarghi L., Jagodic M., Drofenik M. 2011. "Hexaferrite/Polyethilene Composite Coating Prepared wirh Flame Spay", Material Letters, Vol. 65, Hal. 534-536.

[11] Phang, S.W., Tadakoro, M., Watanabe, J,dan Kuramoto, N. 2008. "Synthesis, Characterization and Microwave Absorbtion Property of Doped Polyaniline Nanocomposite Containing TiO2 Nanoparticles and Carbon Nanotube,"Synthetic Metals, No.158, hal. 251-258. 